\section{DROGAS, BIOPOLÍTICA E SUBJETIVIDADE: INTERFACES ENTRE PSICANÁLISE E GENEALOGIA}

\section{Drugs, Biopolitics and Subjectivity: Interface between Psychoanalysis and Genealogy}

\section{Drogas, Biopolítica y Subjetividad: Interfaces entre Psicoanálise y Genealogia}

\section{Drogues, Biopolitique et Subjectivité: Interfaces entre Psychanalyse et Généalogie}

\section{Resumo}

Nos tempos antigos, o consumo de drogas consistia numa prática cultural marcada por prédicas dietéticas. Contudo, na Época Moderna, as drogas tornaram-se objeto do capitalismo mercantilista e, em seguida, sua produção foi inovada e ampliada a partir das operações técnicas e científicas no século XIX. No século XX, o controle biopolítico sobre os psicoativos levou à medicalização e criminalização de seu consumo. Neste artigo, objetivamos analisar os efeitos subjetivos da biopolítica das drogas. Buscaremos uma aproximação da teoria lacaniana dos discursos com a genealogia foucaultiana. Constatamos que a produção subjetiva do toxicômano foi contemporânea à produção do homo oeconomicus, representando o seu avesso. A categoria toxicômano constituiu-se na fronteira entre a Medicina e o Direito, legitimando intervenções policiais e higienistas próprias do "Estado de exceção". Concluímos que a capitalização e a fabricação tecnocientífica das drogas e seu agenciamento biopolítico estão em função do dispositivo de gozo próprio da pós-modernidade.

Palavras-chave: biopolítica; toxicomania; subjetividade; psicanálise; discurso.

\section{Abstract}

In ancient times, the consumption of drugs consisted of a cultural practice marked by dietary preaching. However, in modern times, drugs have become objects of mercantile capitalism and its production was innovated and expanded from the scientific and technical operations in the nineteenth century. In the twentieth century, the biopolitical control over the psychoactive led to the medicalization and criminalization of its consumption. This article aims to analyze the subjective effects of biopolitics drugs. We seek an approximation of the Lacanian theory of discourse to Foucault's genealogy. We found that the subjective production of the drug addict was contemporary to the production of homo economicus, representing its reverse. The "drug addict" category constitutes the border between medicine and law, legitimizing police and hygienist's interventions from the Exception State. We conclude that the capitalization and techno-scientific production of drugs and their bio-political agency are due to the own enjoyment device of post modernity.

Keywords: biopolitics; addiction; subjectivity; psychoanalysis; speech.

\section{Resumen}

En los tiempos antiguos, el consumo de drogas consistía en una práctica cultural marcada por prédicas dietéticas. Sin embargo, en la Época Moderna, las drogas se cambiaron a

\section{Biopolítica e Subjetividades \\ Contemporâneas}


objetos del capitalismo mercantilista y su producción se quedó innovada y amplia después de las operaciones técnicas y científicas en el siglo XIX. En el siglo XX, el control biopolitico de los psico-activos llevó a la medicalización y a la criminalización de su consumo. En este artículo objetivamos evaluar los efectos subjetivos de la biopolitica de las drogas. Buscaremos una cercana aproximación de la teoría lacaniana de los discursos con la genealogía de Foucault. Comprobamos que la producción subjetiva del toxicómano fue contemporánea a la producción del homo economicus, representando su revés. La categoría "toxicómano" se constituyó en la frontera entre la Medicina y el Derecho, legitimando intervenciones policiales e higienistas propias del Estado de Excepción. Concluimos que la capitalización y la fabricación técnico-científica de las drogas y su negociación biopolítica están en función del dispositivo de gozo propio de la post- modernidad.

Palabras clave: biopolitica; toxicomania; subjetividad; psicoanálisis; discurso.

\section{Résumé}

Ancièrement, la consommation de drogue était une pratique culturelle marquée par des discours diététiques. Cependent, à la Modernité les drogues sont devenues des objets du capitalisme mercantiliste et sa production a été innovée et amplifiée à partir des opérations technique et scientifique au XIXe siècle. Au XXe siècle, le crontôle biopolitique des psycotropiques a résulté à la médicalisation et criminalisation de sa consommation. Cet article a le but d'analyser les effets subjectifs de la biopolitique des drogues. On recherche une approximation entre la théorie lacanienne des discours et la généalogie foucaultienne. On peut vérifier que la production subjective du toxicomane a été contemporaine à la production du homo economus en représentant son inverse. La catégorie " toxicomane » se trouve à la frontière entre la Médecine et le Droit en légitimant des interventions policiers et higiéniste propres de l'État d'Exception. On conclut que la captalisation et la fabrication téchnoscientifique des drogues et son agencement biopolitique sont à la fonction de dispositif de jouissence propre de la post-modernité.

Mots-clés: biopolitique; toxicomanie; subjectivité; psychanalyse; dircours.

Qual a correlação genealógica entre o uso abusivo de drogas, a lógica biopolítica imanente à estrutura discursiva na contemporaneidade e os modos de subjetivação próprios de nossa sociedade? Essa é uma problemática que nos permite encaminhar uma possível e provável articulação entre a psicanálise e a genealogia foucaultiana.

Partimos da consideração de que, longe de ser uma questão exaurida, a adiç̧ão continua a se apresentar como o paradigma central do lugar da economia de gozo nos modos de subjetivação de nossa época. No que se refere ao quadro geral dos adoecimentos psíquicos nos laços sociais, o adicto vem se sobrepondo ao clássico louco enquanto figura de exclusão da cena social, substituindo-o nos espaços de reclusão nas instituições totais e constituindo, assim, o "tipo ideal" dessa nova população de "desatinados" (Foucault, 1991) pós-modernos.

Partindo da leitura lacaniana sobre os discursos no liame social e considerando a historicidade constituinte dos discursos, assim como o surgimento do discurso do capitalista (Danziato, 2007; Souza, 2003; Žižek, 2008), perguntamo-nos sobre o processo de capitalização das drogas na modernidade, o lugar da ciência nesse processo e seus efeitos de subjetivação.

Junto à teoria dos discursos, faz-se necessário considerar a discussão introduzida por Foucault (2008), e continuada por Agamben (2002), sobre a função do discurso biopolítico na determinação de alguns desses fenômenos. Pois ao mesmo tempo em que se constituiu o que Lacan (2008) denominou de "mercado do gozo", é possível identificar também a emergência do que Foucault (2008) chamou de "mercado da droga". Como veremos, a análise foucaultiana privilegia o contexto biopolítico, momento de impasse quanto aos agenciamentos governamental, econômico e jurídico sobre as drogas.

A biopolítica, enquanto forma de poder/produção que tem por objeto o corpo populacional, apresenta-se cada vez mais como a tônica dos modos de subjetivação do contemporâneo. Privilegiando a historicidade da discursividade econômica neoliberal, Foucault (2008) revela a capitalização das instituições sociais e sua política de gestão das populações. É nesse contexto que o consumo desenfreado de drogas surge como problema biopolítico, fazendo convergir diferentes saberes, discursividades, instituições e proposições legais, ou seja, apontando para a constituição de um "dispositivo das drogas".

Como situar a psicanálise nesse contexto? Enquanto discurso, ela também tece considerações sobre a toxicomania, sendo por ela interrogada, teórica e clinicamente (Rosa, 2006). Dessa forma, atenta para a relação estreita entre a toxicomania e o que Lacan (1978) denominou de "discurso do capitalista", revelando a dependência ao objeto e à lógica da recuperação do mais-de-gozar (Lacan, 2008), o que entende como um sintoma do laço social contemporâneo sendo sintoma aqui entendido como o que sinaliza para algo que não anda bem (Lacan, 2008).

Frente à complexidade do objeto droga, que aponta insistentemente para as impossibilidades freudianas do governar, do educar, do analisar e do fazer desejar (Freud, 1937/1996; Lacan, 1992), propomos neste trabalho situar historicamente a dimensão biopolítica das drogas e suas consequências subjetivas, buscando subsídios para pensar a teoria e a práxis psicanalítica. 
Mesmo sabendo das críticas e ambivalências de Foucault em relação à psicanálise, acreditamos que o recurso à perspectiva genealógica foucaultiana possibilitanos uma leitura, assim como um intercâmbio e algumas aproximações, restando resguardadas as diferenças conceituais de ambos os campos. Apostamos numa aproximação entre o conceito foucaultiano de dispositivo com a teoria dos discursos elaborada por Lacan, a partir da noção de história implícita na conceituação de ambos. Vale ressaltar que, apesar das diferentes vias de pensamento entre Lacan e Foucault, (um psicanalista e o outro filósofo), interessa-nos aqui alguns pontos de interseção conceitual em torno das categorias saber, verdade, sujeito e corpo.

Ao perfazer uma breve análise histórico-genealógica das drogas, veremos a emergência dessas categorias, possibilitando nossa abordagem de interface entre Lacan e Foucault. A constituição de um dispositivo das drogas aponta para a constituição de um novo dispositivo, que vai além da preocupação de controlar as taxas de natalidade, mortalidade, a vida e a saúde populacional. Um novo dispositivo que também ultrapassa a gestão dos objetos que incidem no corpo e se ocupa com o gozo dos corpos: um dispositivo de gozo (Danziato, 2006).

Para um melhor entendimento de nossa discussão, acreditamos ser imprescindível uma breve digressão histórica-genealógica das drogas, apresentando antes o método proposto neste trabalho e nossas ferramentas conceituais.

\section{Psicanálise e História: Transitoriedades}

Como procedimento metodológico, instigados por uma "história do presente"1 (Foucault, 1993), buscaremos realizar uma análise histórica e genealógica das relações de poder/produção em torno das drogas, considerando seu contexto biopolítico e suas implicações subjetivas e sociais em interface com a teoria lacaniana dos discursos.

A possibilidade de uma aproximação entre a psicanálise e a história não significa uma superinterpretação dos fatos históricos a partir dos conceitos psicanalíticos. Certeau (2011) considera a psicanálise e a historiografia como campos afins ao introduzir a ficção no fazer científico:

A escrita historiográfica cria 'a-topias'; ela abre 'nãolugares' (ausências) no presente; às vezes, ela organiza sistematicamente pontos de fuga na ordem dos pensamentos e das práticas contemporâneas. Ela colocase, então, do lado do sonho. Eis o que já havia sido afirmado por J. Benthan e que a análise freudiana, de maneira mais aprofundada, nos ensinou: a alteridade do

\footnotetext{
1 Em linhas gerais, trata-se de uma análise histórica que parte das problemáticas do presente, como bem demonstrou o estudo foucaultiano sobre as prisões e seu consequente engajamento político.
}

real ressurge na ficção. (Certeau, 2011, p. 185)

O historiador opera a partir da ausência do outro, produzindo o passado a partir de uma série de operações de recortes, construções e arranjos. A "operação historiográfica" gira em torno de uma falta, de uma ausência, fazendo com que a escrita (ou escritura) do historiador seja sempre inacabada (Certeau, 2010).

Consideramos esse "ausente da história" uma referência ao registro do real elaborado por Lacan que, diferente da realidade, consiste no limite da simbolização. O tempo, enquanto um impossível de capturar e dominar, possui sua faceta de real. Danziato (2009) propõe uma aproximação possível entre psicanálise e a genealogia foucaultiana a partir da consideração de um real, um furo na história que produz movimento:

[...] há uma proximidade entre as concepções de história entre Foucault e Lacan, já que em ambas encontramos uma destituição dos significados profundos, ou do sentido da história. Para ambos, não há sentido, não há sujeito da história, já que ela avança na lida com o real e o corpo. (Danziato, 2009, p.191)

Nesse sentido, a produção dos quatro discursos radicais e dos discursos de exceção - o discurso do capitalista proposto por Lacan e o "discurso do a-viciado" sugerido por Souza (2003) - pode ser situada historicamente. Mais do que isso, considerar um real na história consiste em levar em conta o sexo, a morte, a vida e o corpo como impossíveis de uma simbolização total. Danziato (2009) atenta que a proposição foucaultiana de uma genealogia aborda as relações de poder em torno do corpo e das práticas corporais. Daí um interesse comum entre Lacan e Foucault por temas afins - o corpo, o sexo, a vida e a morte -, apesar de seus campos distintos do saber.

Enquanto procedimento metodológico crítico, a genealogia está na fronteira entre o corpo e a história: “A genealogia, como análise da proveniência, está, portanto, no ponto de articulação do corpo com a história. Ela deve mostrar o corpo inteiramente marcado de história e a história arruinando o corpo" (Foucault, 1979, p. 22).

Nessa perspectiva, situamos o objeto droga como um elemento que também está entre o corpo e a história, e, portanto, também escreve a genealogia do corpo moderno. O corpo é a fonte e o espaço do gozo, conforme Lacan (2012). Isso nos leva a considerar que a incidência das drogas no corpo interfere não só na economia de gozo do sujeito como também na economia política no laço social, e ambas se articulam nos interstícios dos processos de subjetivação. Um exemplo disso é a produção cultural das bebidas e das drogas, que foi acompanhada pela produção de textos e discursos normativos-subjetivantes. 


\section{Aphrodisia, Dietética e Phármakon}

Ao problematizar o uso dos prazeres, Foucault (1994) dedica um capítulo de sua História da Sexualidade para abordar os aphrodisia, que na cultura grega se referiam aos atos e contatos que proporcionavam prazer. A comida, a bebida e o sexo eram prazeres que tocavam diretamente o corpo, causando sensações intensas e, por isso, tendenciosas à intemperança. Daí a recomendação médica e filosófica sobre a moderação nas práticas alimentares e sexuais, evitando o excesso, o desperdício e a perda do governo de si. Por outro lado, os prazeres considerados mais nobres eram relacionados aos objetos que não tocavam diretamente a superfície corporal, como a audição, a visão e o olfato. De modo geral, o uso dos prazeres não se tratava de uma moral proibicionista, e sim de uma ética prescritiva:

[...] em todo caso nada que se assemelhasse as longas listas de atos possíveis que serão encontrados nos penitenciais, nos manuais de confissão ou nos livros de psicopatologia; nenhum quadro que sirva para definir o legítimo, o permitido ou o normal, e a descrever a vasta família dos gestos proibidos. (Foucault,1994, p. 38)

Havia, portanto, entre os cidadãos da pólis grega, uma preocupação com os excessos expressa na série de recomendações que não pretendia eliminar as forças que conduziam os prazeres, mas destiná-las uma forma regulada, temperante. De forma abrangente, a dietética consistia numa "técnica da existência" (Foucault, 1994, p. 97), uma reflexão sobre si e sobre seu corpo, apoiada, mas não submissa, aos preceitos médicos e filosóficos sobre a as medidas adequadas em torno da comida, do sexo, dos exercícios físicos e do sono. Nessa mesma lógica, os regimes excessivos não eram recomendados, pois comprometeriam o ideal da temperança. A dietética não consistia na obediência restrita ao saber do outro, e sim numa reflexão ética individual.

A preocupação com os objetos que poderiam ser nocivos ou benéficos ao corpo está presente também na concepção antiga do phármakon, termo que indicava a interferência de um elemento artificial no curso natural da vida. A ingestão farmacológica e de substâncias inebriantes produziam efeitos artificiais no corpo, suspendendo a dor, o adoecer e o sofrimento. Por ser artificial, o phármakon era considerado por vários médicos e filósofos como elemento nocivo, pois contrariava o processo natural do Logos. Daí a concepção corrente do phármakon como elemento fronteiriço entre o remédio e o veneno (Derrida, 1997).

$\mathrm{Na}$ tradição médica hipocrático-galênica, produtos phármakons, como as especiarias, serviam para regular o equilíbrio dos humores corporais: o sangue, a fleuma, a bílis amarela e a bílis negra. Substâncias temperantes eram acrescidas à dieta alimentar, com a finalidade de ajustar os humores conforme suas qualidades: quente, seco, frio e úmido. Essa concepção médica da teoria humoral perdurou até a Idade Média, época em que a moral cristã condenava os excessos da carne em favor de uma dietética temperante. Em consonância com essa moral medieval do consumo temperante, no campo da economia, a noção do justo preço da mercadoria norteava as relações comerciais, condenando o valor excessivo dos produtos, a usura e a luxúria (Carneiro, 2005). Com a modernidade e a lógica capitalista, inaugurase uma nova moral, pautada nos excessos.

\section{A Capitalização das Drogas e a Ciência}

O termo droog, raiz da palavra "droga", tem sua origem no comércio marítimo holandês do século XVI para designar os produtos negociados nos portos. A partir de então, "droga" foi o termo corrente para designar especiarias como noz-moscada, açúcar, café, chocolate, tabaco, chá, produtos que possuíam uma função alimentar, medicamentosa e estética (Carneiro, 2005). Dessa forma, as drogas modernas podem ser consideradas as principais mercadorias do mercantilismo e do sistema colonial europeu.

Durante os séculos XVII e XVIII, a produção em larga escala das bebidas alcoólicas serviu como eixo econômico importante do mercantilismo estatal. Contudo, essa fabricação em série teve como efeito o declínio de seus referenciais simbólico-culturais. De uma fabricação doméstica e mediada por rituais campestres, as bebidas alcoólicas passaram a ser produzidas em série e em grandes quantidades (Carneiro, 2005).

O Brasil colonial despontou como grande produtor de aguardente, bebida que desde então se tornou referência simbólica e identitária da cultura brasileira. A mesma bebida também serviu como instrumento de colonização da "civilização" europeia ao devastar os referenciais simbólicos da cultura negra e indígena, tal como descreveu Cascudo (2006).

Com a formação do capitalismo imperialista, o mercado das drogas foi utilizado como ferramenta de dominação política e econômica. O império britânico promoveu, no século XIX, as Guerras do Ópio (1839 a 1842 e 1856 a 1860) contra a China, obrigando este país a receber como pagamento ópio em vez de prata na importação de chá. Outros países europeus, como França e Espanha, também impuseram o comércio de drogas às suas colônias na Indochina e Filipinas (Escohotado, 2002). Tais fatos revelam a função do Estado como agenciador da violência em função de seus interesses soberanos.

Ainda no século XIX, o avanço técnico-científico fez surgir as drogas sintéticas, que provocaram rupturas no campo do conhecimento e das práticas medicinais. Com o trabalho laboratorial de isolamento dos componentes 
químicos das drogas, foi possível uma produção sintética de novas substâncias, como a morfina (1804), a codeína (1832), a cocaína (1859) e a heroína (1874) como produtos fármacos (Carneiro, 2005).

A morfina e heroína foram comercializadas pelas empresas alemãs Merck e Bayer, respectivamente. Derivadas do ópio, essas substâncias eram utilizadas como anestésicos cirúrgicos, analgésicos e xaropes, devido às suas propriedades narcotizantes. Daí também a denominação de entorpecentes, por causarem torpor e sonolência (Carneiro, 2005).

Por outro lado, fortificantes e excitantes à base de coca também foram produzidos, sobretudo para aqueles considerados neurastênicos. O entusiasmo de Freud sobre as possibilidades terapêuticas da cocaína não foi um fato isolado. Conforme Santiago (2001), os estudos freudianos sobre a coca foram tributários às pesquisas científicas de Helmholtz e Brüke, que buscavam os fundamentos termodinâmicos do funcionamento vital.

Considerando a escrita do texto O Mal-estar na Civilização (Freud, 1930/2011) em seu contexto histórico, marcado pelos efeitos da modernidade (Birman, 2006), podemos apreender melhor a indicação freudiana sobre o uso das substâncias químicas como forma de suspender o sofrimento e o mal-estar via narcotização corporal:

[...] O serviço dos narcóticos na luta pela felicidade e no afastamento da miséria é tão valorizado como benefício, que tantos indivíduos como povos lhes reservaram um sólido lugar em sua economia libidinal. A eles se deve não só o ganho imediato de prazer, mas também uma parcela muito desejada de independência em relação ao mundo externo. Sabe-se que com ajuda do 'afasta-tristeza' podemos nos subtrair à pressão da realidade a qualquer momento e encontrar refúgio num mundo próprio que tenha melhores condições de sensibilidade. É notório que justamente essa característica dos entorpecentes determina também o seu perigo e nocividade. Em algumas circunstâncias eles são culpados pelo desperdício de grandes quantidades de energia que poderiam ser usadas na melhoria da sorte humana. (Freud, 1930/2010, pp. 3334 , [grifos nossos])

Nessa mesma época, o alcoolismo (1843) e a toxicomania (1875) sugiram como categorias médicopatológicas. À medida que a indústria de bebidas, do tabaco e dos fármacos conquistava consumidores ávidos pelos objetos da ciência, o alcoolismo e a toxicomania sugiram como problemáticas sociais dos tempos modernos (Escohotado, 2002).

A medicina social, em sua face estatal, urbana e trabalhista (Foucault, 2007), promoveu mudanças significativas no espaço da cidade e nos hábitos cotidianos em torno dos ideais de higiene e salubridade, incidindo nos processos de subjetivação modernos. Nas primeiras décadas do século XX, o alcoolismo foi associado à pobreza, tornando-se objeto de intervenção médica e policial, não sendo rara a estreita relação entre o asilo, a cadeia e a colônia correcional. Em contrapartida, a toxicomania era descrita como um problema emergente, porém, privado de consumidores abastados socialmente.

No início do século XX, a ampliação do movimento de higiene mental em vários países, incluindo o Brasil, difundiu a ideia de que era possível prevenir-se contra as doenças mentais. O álcool era concebido como uma substância venenosa e causa geral das doenças nervosas, da violência e da criminalidade.

Nessa época, houve uma preocupação dos estados em fomentar leis internas e acordos internacionais para controlar e restringir a produção, o comércio e o consumo do ópio e seus derivados. Em 1911, ocorreu a I Conferência Internacional do Ópio e de Seus Derivados em Haia, que representou o início de uma série de encontros internacionais para a discussão de medidas políticas e jurídicas de controle e restrição (Escohotado, 2002).

$\mathrm{Na}$ década de 1920, vigorou nos EUA a Dry Law (Lei-Seca), que proibia a produção e comercialização de bebidas alcoólicas em território nacional. Nesse contexto, em vários países, inclusive no Brasil, ocorreram campanhas antialcoólicas, a partir da atuação do movimento higienista, que privilegiavam a abstinência e a proibição como medidas eficazes contra o alcoolismo, considerado um mal degenerativo e hereditário, e contra o álcool, compreendido como uma substância venenosa. Na Alemanha nazista da década de 1930, vários alcoolistas foram esterilizados conforme o programa higienista-eugenista do III Reich (Costa, 2007a). Nesse sentido, podemos aproximar o alcoolista do paradigma de uma "vida que não vale ser vivida", tal qual a do homo sacer, passível de intervenções asilares e policiais (Agamben, 2002).

Essa mesma lógica que conjugava abstinência e proibição foi transferida para as ações políticas de combate aos entorpecentes e para o tratamento da toxicomania. Em 1937, o cultivo e o uso da maconha foram proibidos nos EUA. O argumento corrente era de que os entorpecentes representavam uma ameaça à vida e à ordem social. Não à toa, determinadas substâncias eram associadas às classes perigosas, inferiores e estrangeiras: a cannabis aos mexicanos, o gim aos irlandeses, a cocaína aos negros e o ópio aos chineses (Escohotado, 2002).

A partir da década de 1930, surgiram as primeiras instituições de "temperança" anônimas baseadas nos ideais de fraternidade e sobriedade. O grupo Alcoólicos Anônimos (AA), surgido em 1935 nos EUA, serviu de modelo para os demais grupos de temperança, como os Narcóticos Anônimos (NA), espalhados por todo o mundo (Carneiro, 2010). Acreditamos que essas instituições contribuíram para a concepção do alcoolismo e da toxicomania como 
uma doença individual.

Nas últimas décadas do século XX, o mercado das drogas ilícitas prosperou, obtendo lucros exorbitantes. Essa foi a mesma época da ascensão da indústria dos psicofármacos. Diferente das outras drogas, o crack foi inserido de forma peculiar nos subúrbios da cidade, como objeto bruto alternativo à cocaína. Escohotado (2002) observa que, diferente das outras substâncias psicoativas que se tornaram ilegais, o crack já surgiu como produto ilegal. Fabricado desde os anos 1980 como um produto alternativo à cocaína, porém, mais barato e de menor qualidade, possuía efeitos excitantes mais intensos e menos duradouros.

Desprovido de referências culturais ou mesmo medicinais, o crack se apresenta como uma "droga nua" para utilizarmos de uma analogia ao termo agambeniano "vida nua" (Agamben, 2002) -, cujo consumo ultrapassou os limites suburbanos. Tal fato apresenta-se de forma relevante, pois substâncias como o crack relevam os efeitos de dessubjetivação que podem ocorrer quando um objeto oriundo da união entre capitalismo e tecnociência é introduzido no laço social sem qualquer referência simbólica que norteie seu consumo.

Entre o sujeito e o objeto droga há um "tecido significante" intermediando as práticas de consumo (Santiago, 2001). Esse tecido se apresenta como um revestimento de significantes presentes no Outro da cultura, funcionando como uma baliza nos laços sociais, permitindo ao sujeito usar, mas não sucumbir à droga. A referência ao crack como uma "droga nua" indica a ausência dessa malha simbólica.

\section{Biopolítica, Mercado das Drogas e Subjetivação}

Foucault (2008) perfaz uma análise minuciosa da política neoliberal contemporânea, sobretudo da que foi construída em solo norte-americano, para situar o surgimento da biopolítica. Diferente dos modelos francês e alemão, o neoliberalismo norte-americano se distinguia por levar a análise econômica para campos não propriamente econômicos, como a vida populacional, a educação, a segurança e a saúde. Tais fatores, conjugados, formam a teoria do capital humano. A busca pela qualidade de vida, pelo desenvolvimento populacional e pelo bom padrão genético configuram as metas do capital humano. Como efeito subjetivo, tem-se a produção individual do homo oeconomicus como um "empresário de si mesmo", ou ainda, uma "micro-empresa de si".

Consideramos que, não por acaso, tanto o alcoolista como o toxicômano emergem aí, representando o avesso dessa construção, pois escapam a lógica da produtividade material e social. Funcionam, portanto, como um sintoma, aqui definido como o que sinaliza que algo não anda bem
(Lacan, 2008).

Outro aspecto do neoliberalismo norte-americano diz respeito à gestão da criminalidade. Foucault (2008) ressalta que a interferência da análise econômica no campo jurídico tem como efeito a produção de uma legislação pragmática que preza pela eficiência penal. $\mathrm{O}$ crime passa a ser definido como aquilo que viola o interdito. Dessa forma, não se pune mais o criminoso, mas seu ato. Contudo, a sociedade não tolera leis rígidas, fazendo com que a legislação passe a agenciar a criminalidade, mas não acabe com ela. A aplicação da lei pode fazer uso de instrumentos que a auxiliam e a qualificam, produzindo um "enforçamento". Esse "enforçamento da lei" é característico no controle biopolítico do mercado das drogas:

[...] A droga se apresenta, portanto, como um mercado, e digamos que, até a década de 1970 mais ou menos, a política de enforço da lei em relação à droga visava essencialmente reduzir a oferta da droga. Reduzir a oferta de droga, a oferta de crime de droga, de delinqüência de droga - reduzir essa oferta queria dizer o que? Queria dizer, é claro, reduzir a quantidade de droga posta no mercado, e reduzir a quantidade de droga no mercado queria dizer o quê? Controlar e desmantelar as redes de refino, controlar e desmantelar também as redes de distribuição. (Foucault, 2008, p. 351)

Essa referência foucaultiana sobre a presença de um mercado das drogas no interior da biopolítica nos serve como cerne de análise sobre os efeitos subjetivos dos novos rearranjos entre capitalismo e ciência. Importante ressaltar que as drogas sintéticas, comercializadas nas margens da criminalidade, são por excelência um objeto científico. Vale ressaltar, considerando o percurso históricogenealógico desenvolvido anteriormente, que a constituição de um mercado das drogas é anterior ao contexto histórico problematizado por Foucault (década de 1970). Nesse sentido, a capitalização e a mercantilização das drogas foi anterior a sua cientifização de meados do século XIX. A novidade do século XX foi tornar a droga um produto científico por excelência.

\section{Lacan e o Mercado do Gozo}

Podemos ainda considerar o mercado das drogas como um sintoma do que Lacan (2008) denomina de mercado do gozo no contexto da modernidade.

No seminário de Um Outro ao outro, Lacan (2008) elabora uma leitura inovadora do Capital de Marx, tecendo considerações sobre o estatuto do objeto $a$ e sua relação com o discurso. Embora não tenha ainda formalizado a topologia dos quatro discursos e o discurso do capitalista, situa a partir da equivalência entre mais-valia e o mais- 
gozar a emergência do "mercado do gozo" como efeito da discursividade capitalista na modernidade:

É no discurso sobre a função da renúncia ao gozo que se introduz o termo objeto $a$. O mais-de-gozar como função dessa renúncia, sob o efeito do discurso, eis o que dá seu lugar ao objeto $a$, tal como no mercado, a saber, no que ele define algum objeto do trabalho humano como mercadoria, assim como cada objeto porta em si mesmo alguma coisa da mais-valia, assim o mais-de-gozar é o que permite o isolamento da função do objeto $a$. (Lacan, 2008, p. 17)

Se a mais-valia em Marx consiste no trabalho não remunerado, o que gera o lucro ao capitalista, o maisgozar se revela como uma renúncia ao gozo, um resto da condição de linguagem do humano que faz operar o objeto a. Uma faceta característica do capitalismo será a busca constante de recuperar esse objeto perdido do mais-gozar, ofertando objetos, "latusas" (Lacan, 1992) que pretendem obturar imaginariamente a falta constituinte do sujeito. Nas transmutações do capitalismo desde seu surgimento mercantilista, imperialista, financeiro -, vimos constituir-se o próprio mercado da droga, podendo ser lido agora como o efeito da capitalização do mais-gozar (Lacan, 2008).

Lançamos como hipótese que a constituição e o estatuto atual do mercado da droga, incluindo seus efeitos de dessubjetivação, estão relacionados ao movimento discursivo e aos desdobramentos do que Lacan nomeou como discurso do capitalista. Para uma melhor análise dessa consideração, vale aqui contextualizar o conceito de discurso no ensino, de Lacan.

Façamos, então, um breve esclarecimento da topologia dos quatro discursos desenvolvida no seminário $O$ Avesso da Psicanálise (Lacan, 1992), momento no qual define o discurso como "um discurso sem palavras" (p.11).

A partir do axioma que propõe que "um significante representa um sujeito para outro significante" (Lacan, 1998), Lacan estabelece os discursos, formalizando os elementos mínimos na constituição do laço social, a partir de quatro lugares, que virão a ser ocupados pelos quatro significantes que os matemiza: $\$, \mathrm{~S} 1, \mathrm{~S} 2$ e $a$.

Os discursos apontam, portanto, para a posição do sujeito perante o outro, considerando a verdade, o saber e o gozo. A disposição desses lugares se articula em função do agente do discurso:

\section{Agente} Verdade
Outro

\section{Produção}

Considerando, então, sua proposição de que o significante (S1) representa o sujeito (\$) para outro significante (S2), produzindo um resto não simbolizável $(a)$, Lacan formaliza o Discurso do Mestre como a estrutura primordial que permite o sujeito estabelecer laço com o outro:

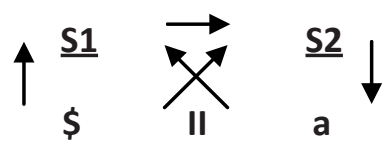

Tal discurso pode ser compreendido como uma releitura lacaniana da dialética do senhor e do escravo, de Hegel. O mestre, ao ocultar sua divisão subjetiva (\$), agencia o trabalho do escravo, que produz a partir de seu saber-fazer. Essa produção é inacessível ao próprio mestre. Na estrutura discursiva, $\mathrm{S} 1$ representa o significante mestre, enquanto $\mathrm{S} 2$, o saber.

Os demais discursos mantêm uma disjunção, proposta por Lacan, entre os lugares da produção e da verdade. Ou seja, nenhum discurso consegue, com sua produção, alcançar ou nomear a verdade, mantendo-se esta na condição de "nãotoda". Os movimentos levogiro e dextrogiro - movimentos horário e anti-horário - dos matemas na estrutura do discurso produzem os outros três: histérica, analista e o universitário.

Destacamos aqui o estatuto do saber na produção dos quatro discursos. Inicialmente como atributo do escravo, o saber, segundo Lacan (2008), teria sido usurpado pelo laço de cumplicidade entre ciência e capitalismo, retornando ao escravo como um objeto no "mercado do saber". Como efeito dessa capitalização, o saber se generaliza, estabelecendo as universidades modernas e se tornando o agente do discurso dominante em nossa sociedade - o universitário.

A ciência moderna, para Lacan (1992), possui uma estruturação histérica ao interrogar constantemente o saber para alcançar a verdade. A busca por um saber totalizante e garantidor da verdade tem seu ápice na filosofia hegeliana, com a formalização do "saber absoluto" articulando a consciência e a razão moderna. Lacan criticou repetidamente em seus seminários essa constatação hegeliana do saber absoluto na modernidade, chegando a considerar esse filósofo como "o mais sublime dos histéricos".

A constatação lacaniana foi que a modernidade revela a própria disjunção entre saber e verdade, como bem indica o cogito cartesiano. Ao se deparar com o real, Descartes produziu uma sutura e recuperou um Outro divino como garantidor do saber e da verdade. Por sua vez, Hegel propôs um saber totalizante pretendendo esgotar o real.

A psicanálise, desde sua origem como discurso, leva em consideração a divisão subjetiva e a impossibilidade em alcançar a verdade. A clínica psicanalítica surge como discurso quando Freud abdica de um lugar de mestre e passa a sustentar um suposto saber diante da histérica. O lugar do analista enquanto semblante do objeto $a$ provoca uma histericização na fala do analisando ao se deparar com 
sua divisão subjetiva.

Dessa forma, há, com a formalização dos quatro discursos, um percurso do saber na história. Do saberfazer escravo, perpassando o saber universalizado e mercantilizado, até a expropriação do saber pelo capitalista, assistimos ao nascimento da ciência moderna com seu traço histérico. O discurso do analista surgiu como um "sintoma da modernidade", um "giro do saber na história" (Lacan, 2008), e permitiu a leitura da formalização os demais discursos.

A modernidade inaugurou também uma nova mestria com o capitalista. O discurso do capitalista se apresentou a Lacan como uma exceção aos já mencionados discursos radicais. Na ocasião de uma conferência em Milão, Lacan (1978, p. 8) propôs uma torção no discurso do mestre, produzindo um novo matema representante de uma exceção aos quatro discursos, pois consistia numa ruptura do laço social. A esse discurso Lacan nomeou como do capitalista, posto aqui como o mestre moderno:

[...] porque el discurso capitalista es ahí, ustedes lo ven ... una pequena inversión simplesmente entre el S1 e \$... que es el sujeto... es suficiente para que esto marche sobre ruedas no puede marchar mejor, pero justamente marcha demasiado rápido, se consuma, se consuma tan bien que se consume. (Lacan, 1978, p. 8)

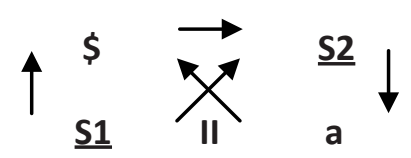

Destacamos o caráter de ruptura com o laço social, dada a prevalência do objeto ao qual o sujeito possui acesso de forma direta e irrestrita (Souza, 2003). O estatuto do saber se modifica, tornando-se acessível, através da parceria entre ciência e tecnologia, na produção de objetos de consumo acessíveis ao sujeito, cujo efeito é a obliteração da castração.

O sujeito, impulsionado pelo capitalista, produz, através do saber tecnocientífico, objetos de consumo. Lacan (1992, p. 153) atenta para os efeitos dos objetos do capitalismo como "latusas", expostos nas vitrines e em cada esquina da cidade, comparando-os a "ventosas". Ofertados para serem consumidos rápida e repetidamente, esses objetos suspendem a castração e o mal-estar.

Braunstein (2010) observa que, nessa mesma conferência, Lacan sinaliza a constituição de um "pós", um "mais além" ao discurso do capitalista, caracterizado pela hegemonia do mercado. Neste, a prevalência do objeto comandaria o sujeito em detrimento do próprio capitalista como agente discursivo. O próprio objeto seria portador de um saber, situação própria dos novos objetos tecnológicos. Nessa lógica discursiva de exceção, a qual o autor nomeia como "discurso dos mercados", a falência do Outro leva o sujeito a buscar um S1 que lhe sirva de referência identitária. Quanto ao matema desse discurso de exceção, ele teria a mesma estrutura do discurso do analista, fato que aponta para a relação avessa entre a psicanálise e a discursividade capitalista. Žižek (2008) também constata essa prevalência do objeto como agente em detrimento do mestre capitalista, corroborando para uma nova formação discursiva com essa mesma topologia do discurso do analista.

Seguindo as variações do discurso de exceção ao laço social, Souza (2003) chega a propor o "discurso do $a$-viciado" como mais um discurso de exceção ao laço social. Nesse discurso, que além da posição toxicômana aponta para outras dependências, o objeto ocupa um lugar de dominância sobre o sujeito, que fica impossibilitado de ter acesso ao significante mestre. Diferente do discurso capitalista, no qual o objeto sempre se renova em função do consumismo, o objeto no discurso do a-viciado provoca um estreitamento do fantasma fundamental.

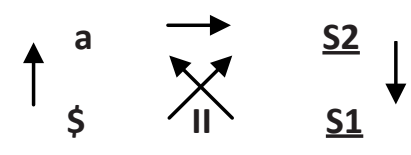

A posição adicta do sujeito, sua pregnância ao objeto, é justificada por um saber. Diferente dos discursos radicais, em que o saber no lugar do outro remete a uma dádiva paterna, no $a$-viciado o estatuto do saber é modificado, funcionando como um constructo fora da referência paterna.

É por essa via, portanto, que aproximamos a noção lacaniana de discurso, enquanto um aparelho que abarca o dito e o não dito, ao dispositivo foucaultiano.

\section{Discurso e Dispositivo}

Dispositivo foi um conceito cunhado por Foucault para referir-se ao conjunto de práticas, instituições, discursos, em torno da sexualidade:

Através deste termo tento demarcar, em primeiro lugar, um conjunto decididamente heterogêneo que engloba discursos, instituições, organizações arquitetônicas, decisões regulamentares, leis, medidas administrativas, enunciados científicos, proposições filosóficas, morais, filantrópicas. Em suma, o dito e o não dito são os elementos do dispositivo. O dispositivo é a rede que se pode estabelecer entre estes elementos. (Foucault, 2007, p. 244)

Esse dispositivo da sexualidade se constituiu no século XIX a partir da família como instrumento de governo e produção de subjetividade, desencadeando o que Foucault 
denomina de uma "colocação do sexo em discurso". Ou seja, o século XIX, longe de ser o período de maior repressão à sexualidade, se configurou como o momento histórico onde se mais produziu discursos e práticas sobre o sexo. Entre as estratégias e poder-saber do dispositivo da sexualidade, ele discrimina: a pedagogização da sexualidade infantil, a histericização do corpo da mulher, a patologização das sexualidades perversas e a medicalização das condutas de procriação (Foucault, 1988). Todas essas estratégias tinham como efeito a produção incessante de discursos e práticas disciplinares sobre sexo, assim como da instalação de uma correlação entre a fala, o desejo e a verdade.

Seguindo essa perspectiva, para Foucault, a psicanálise freudiana teria se apresentado como mais uma discursividade sobre sexual, porém, distinta da tendência científica de sua época, inclinada a conceber a sexualidade como uma perversão no campo da patologia, com aspectos hereditários e degenerativos.

Acompanhando Foucault e aplicando seu pensamento ao nosso objeto de pesquisa, teríamos que pensar num "dispositivo das drogas" como uma série de saberes, práticas, enunciados e regras em torno da produção e controle do consumo de drogas. Nas palavras de Vargas (2008, p. 55):

Longe de serem unívocas, as relações que a maioria das sociedades contemporâneas mantém com as drogas são ambivalentemente marcadas pela repressão e pela incitação ao consumo. Por conta disso, creio ser possível afirmar [...] que tais relações configuram uma espécie de dispositivo das drogas, num sentido próximo ao que Foucault. (1982c) estabeleceu para o 'dispositivo da sexualidade'. Problema de repressão e de incitação, a droga, tal como o sexo, não existiu desde sempre, sendo uma invenção social relativamente recente.

A partir daí, poderíamos também estender a critica foucaultiana à noção de "hipótese repressiva" da sexualidade (Foucault, 1988) para a questão das drogas na atualidade, ou seja, o mecanismo de repressão expresso na política de proibição a determinadas substâncias funciona como máquina de controle que regula a produção, mas não a extingue. Da mesma forma, uma série de saberes e práticas gira em torno do problema do consumo das drogas, ancorados por um processo arqueogenealógico de instalação de uma "capitalização dos prazeres do corpo" (Foucault, 1994), assim como do estabelecimento do discurso do capitalismo (Lacan, 1992) como um discurso dominante no laço social, que estimula e aprecia o consumo dos objetos.

Nessa perspectiva, podemos nos perguntar sobre o atual controle biolítico das drogas. Em primeiro lugar, assistimos à continuidade de uma política de redução da oferta, como bem indica o lema "guerra às drogas" ilícitas.
[...] o consumo da droga, pelo menos no caso dos intoxicados graves e de certo número de drogas, essa demanda de droga é absolutamente inelástica, ou seja, qualquer que seja o preço, o drogado vai querer encontrar sua mercadoria e estará disposto a pagar qualquer preço por ela. (Foucault, 2008, p. 351)

O efeito característico dessa política de redução da oferta de drogas é o aumento de seu valor no mercado, levando os dependentes à criminalidade, para comprar seu produto. $\mathrm{O}$ traficante, enquanto agente no mercado das drogas, lança mão de uma estratégia mercadológica: oferta ao consumidor "elástico" seu produto por um valor baixo e quando o consumidor torna-se "inelástico" o valor do produto aumenta. Uma possível estratégia governamental de controle das drogas e de sua criminalidade decorrente seria ofertar a droga em um valor alto ao usuário iniciante, dificultando seu uso, e aos dependentes, ofertar a droga em valor baixo, evitando crimes relacionados ao seu consumo.

Conforme Rodrigues (2008, p. 98), o proibicionismo funciona como uma técnica biopolítica que autoriza o discurso médico a regular e intervir nas práticas de consumo e, ao mesmo tempo, controla os excessos dos segmentos sociais considerados perigosos: 'O 'fracasso' da proibição, então, potencializa-se em positividade: a guerra perdida contra 'as drogas' significa a guerra diariamente renovada e eficaz contra pobres, imigrantes, negros, camponeses entre outros 'ameaçadores"”.

O cenário dessa "guerra às drogas" é a própria pólis urbana demarcada por territorialidades conflituosas e pela experiência cotidiana da mais-violência.

Em segundo lugar, para sustentar essa "guerra às drogas" e seu consequente controle social, há no contexto biopolítico um permanente estado de emergência, ou ainda, seguindo a conceituação de Agamben (2002), um "Estado de exceção", no qual o poder soberano se sobrepõe a regra. Sobre a "guerra às drogas", a política estatal legitima ações que ferem os princípios democráticos de liberdade, como a reclusão compulsória de toxicômanos, contradizendo os princípios da Reforma Psiquiátrica brasileira.

Outro exemplo desse "Estado de exceção" consiste em intervenções militares nas áreas de tráfico. Para Costa (2007b), haveria nesse recurso à violência bélica uma transição de uma biopolítica para uma tanatopolítica, característica da passagem do discurso da segurança nacional do período ditatorial para o discurso da segurança pública próprio do espaço urbano.

As repercussões subjetivas desse dispositivo são a patologização e a criminalização dos dependentes de substâncias ilícitas, bem como a formação de territórios segregados, como as "cracolândias", situações nas quais podemos observar a produção do que Agamben (2002) denomina de homo sacer. 


\section{Considerações Finais}

A incidência do saber científico na produção de novas substâncias, a princípio medicinais, como a morfina, a cocaína e a heroína, gerou efeitos no mercado dos phármakons contemporâneos, mas com uma consequência crucial: a síntese laboratorial dessas substâncias estabeleceu uma nova relação do sujeito com a droga.

A capitalização do objeto droga, desde o século XVI até os dias atuais, juntamente com sua produção tecnocientífica, destituiu os referenciais simbólicos capazes de mediar uma dietética para ponderar os objetos que atingem o corpo. Consideramos que o atual mercado da droga, com seu funcionamento à margem da lei proibicionista, sua ampla rentabilidade e generalização de consumidores, revela o pleno funcionamento da tese lacaniana sobre a lógica discursiva capitalista, em que a oferta de um produto (químico) suspende a condição de mal-estar, gerando um consumidor ideal fascinado pelo objeto. A droga, em seu estado bruto, "nua", a exemplo do crack, "desterritorializa" o corpo e a polis, apagando os limites simbólicos do sujeito e do laço social.

A associação recorrente entre drogas e violência no espaço da cidade decorre da apropriação da criminalidade urbana das drogas ilícitas, gerando um mercado ilegal altamente lucrativo. A política estatal de controle e regulamentação das drogas, desde a produção das primeiras drogas sintéticas, destacou-se como um "Estado de exceção", ou seja, caracterizou-se como um maisalém das normas jurídicas e da própria noção de Estado democrático (Costa, 2007b).

De modo geral, a biopolítica de prevenção e tratamento do alcoolismo serviu de modelo para a abordagem da toxicomania a partir da segunda metade do século XX. A construção discursiva e subjetiva do toxicômano como doente, criminoso e anônimo resulta, pois, da ação biopolítica que, através de um dispositivo das drogas, agencia a criminalidade e a segregação social. O toxicômano ocupa o lugar de um outro ameaçador da ordem social que deve ser recluso ou, ainda, eliminado.

Quais as implicações dessa biopolítica das drogas para a psicanálise? Primeiramente, consideramos ideia de desnaturalizar a toxicomania, considerando as variantes históricas e discursivas. Em segundo lugar, a capitalização da droga, a partir da tecnociência, aponta para uma busca pela produção de objetos mais sofisticados em narcotizar, excitar os corpos. O dispositivo das drogas e seu controle biopolítico apresentam uma característica própria aos dispositivos contemporâneos: a "dessubjetivação", tal como sugere Agamben (2009). Acreditamos que eles podem também se enquadrar nesse deslocamento de dispositivos na contemporaneidade, o qual sugerimos nomear de um "dispositivo de gozo" (Danziato, 2010) - marca dos efeitos de desubjetivação, muito próprios dos dispositivos contemporâneos (Agamben, 2009).

\section{Referências}

Agamben, G. (2002). Homo Sacer: poder soberano e vida nua. Belo Horizonte: UFMG.

Agamben, G. (2009). O Que é o Contemporâneo? E outros ensaios. Chapecó, SC: Argos.

Birman, J. (2006). Arquivos do Mal-estar e da resistência. Rio de Janeiro: Civilização Brasileira.

Braunstein, N. (2010). O Discurso do Capitalista: quinto discurso? O Discurso dos Mercados: sexto discurso? A Peste: Revista de Psicanálise e Sociedade e Filosofia, 2(1), 143-165.

Carneiro, H. S. (2005). Pequena Enciclopédia da Historia das Drogas e Bebidas: história e curiosidades sobre as mais variadas drogas e bebidas. Rio de Janeiro: Elsevier.

Carneiro, H. S. (2010). Bebida, Abstinência e Temperança: na história antiga e moderna. São Paulo: Editora Senac São Paulo.

Cascudo, L. da C. (2006). Prelúdio da Cachaça. Rio de Janeiro: Global Editora.

Certeau, M. de. (2011). História e Psicanálise: entre ciência e ficção (Coleção História \& Historiografia 3). Belo Horizonte: Autêntica Editora.

Costa, J. F. (2007a). História da Psiquiatria no Brasil (4a ed.). Rio de Janeiro: Garamond.

Costa, A. S. (2007b). A Regra da Exceção: poder soberano e biopolítica na "guerra às drogas". Dissertação de Mestrado em Ciências Políticas, Universidade Federal Fluminense-UFF, Niterói, RJ.

Danziato, L. (2007). O Gozo e o Poder: categorias para pensar as políticas de subjetivação Contemporâneas. Latin Journal of Fundamental Psychopathology on Line, VII(1), 23-34.

Danziato, L. (2009). Existe Uma Genealogia Possível na Psicanálise? Revista Ágora, Rio de Janeiro, XII (2), 185-198.

Danziato, L. (2010). O Dispositivo do Gozo na Sociedade de Controle. Psicologia \& Sociedade, 22(3), 430-437. 
Derrida, J. (1997). A Farmácia de Platão. São Paulo: Iluminuras.

Escohotado, A. (2002). Historia General de Las Drogas (5 ed.). Madri: Espasa.

Freud, S. (1976). A análise terminável e interminável (1937). In Edição Standard das Obras Psicológicas Completas de Sigmund (Vol. XIV). Rio de Janeiro: Imago Editora.

Freud, S. (2010). O mal-estar na civilização, novas conferências introdutórias à psicanálise e outros textos (1930/1936) (P. C. de Souza, Trad.). São Paulo: Companhia das Letras.

Foucault, M. (1988). A História da Sexualidade I - A Vontade de Saber. Rio de Janeiro: Graal.

Foucault, M. (1991). A História da Loucura na Idade Clássica. São Paulo: Perspectiva.

Foucault, M. (1993). Vigiar e Punir: nascimento da prisão $\left(10^{\mathrm{a}}\right.$ ed.). Petrópolis, RJ: Vozes.

Foucault, M. (1994). História da Sexualidade: o uso dos prazeres (Vol. 2, $6^{\mathrm{a}}$ ed.). Rio de Janeiro: Edições Graal.

Foucault, M. (2007). O Nascimento da Medicina Social. In M. Foucault, Microfisicica do Poder (24 ed.). São Paulo: Edições Graal.

Foucault, M. (2008). Nascimento da Biopolítica: curso dado no Collège de France (1978-1979) (Coleção Tópicos). São Paulo: Martins Fontes.

Lacan, J. (1978). Lacan in Itália 1953-1978. La Salamandra.

Lacan, J. (1992). O Avesso da Psicanálise (Seminário, livro 17). Rio de Janeiro: Jorge Zahar.

Lacan, J. (1998). A Instância da Letra no Inconsciente ou a Razão desde Freud. In Escritos. Rio de Janeiro: Jorge Zahar.

Lacan, J. (2008). De um Outro ao outro Seminário, livro 16. Rio de Janeiro: Jorge Zahar.

Lacan, J. (2012). Mais, Ainda (Seminário, livro 20). Rio de janeiro, Jorge Zahar.

Rodrigues, T. (2008). Tráfico, Guerra, Proibição. In B. C. Labate, S. Goulart, E. Mcrae, M. Fiore, \& H. S. Carneiro(Orgs.), Drogas e Cultura: novas perspectivas. Salvador: EDUFBA.
Rosa, M. D. (2006). Gozo e política na psicanálise: a toxicomania como emblemática dos impasses do sujeito contemporâneo. In A. M. Rudge (Org.), Traumas. São Paulo: Escuta.

Santiago, J. (2001). A Droga do Toxicômano: uma parceria cínica na era da ciência. Rio de Janeiro: Jorge Zahar.

Souza, A. (2003). Os Discursos na Psicanálise. Rio de Janeiro: Companhia de Freud.

Vargas, E. V. (2008). Fármacos e outros Objetos Sóciotécnicos. In B. C. Labate, S. Goulart, E. Mcrae, M. Fiore, \& H. S. Carneiro (Orgs), Drogas e Cultura: novas perspectivas. Salvador: EDUFBA.

Zizek, S. (2008). A visão em Paralaxe. São Paulo: Boitempo.

\section{Endereço para correspondência:}

Raul Max

Endereço: Rua Gilder Fernandes Gonçalves, $\mathrm{n}^{\circ}$ 176. Bairro São José. Juazeiro do Norte/CE. CEP: 63024-130

E-mail: raulmax@leaosampaio.edu.br

\section{Endereço para correspondência:}

Leonardo Danziato

Endereço: Rua Álvaro Correia, $\mathrm{n}^{\circ} 455$, ap. 1101, bloco

Bengase. Bairro Mucuripe. Fortaleza/CE. CEP 60165-230.

E-mail: leonardodanziato@unifor.br 